\title{
"Knocking on the door to integration": Korean immigrants' stories of seeking membership in Aotearoa New Zealand society
}

Hagyun Kim, Massey University, Aotearoa New Zealand

\begin{abstract}
INTRODUCTION: While citizens of Aotearoa New Zealand are granted full participation regardless of racial and cultural background, Asian immigrants appear exempt from the benefits of inclusion. For many, immigration is a stress-inducing journey with resultant socio-economic marginalisation adversely impacting on their participation in society.

METHODS: Theoretically underpinned by symbolic interactionism, this Straussian-grounded theoretical study explored how nine South Koreans re-constructed life after immigration. Semistructured interviews were analysed using open, axial and selective coding.

FINDINGS: To re-establish their lives, participants gradually "knock on the door to integration" while retaining a sense of safety in their ethnic community. This process continues until they find a place where they are recognised as a member of society. In this sense, "seeking membership" is what participants try to achieve in the host society.

CONCLUSION: If we want to be at the forefront of efforts to address ethnic minority groups' life-challenges, social work practice must include specific competencies in assisting Asian immigrants, helping them to master their new surroundings and endorse their equal membership in society.
\end{abstract}

KEYWORDS: Korean immigrants; membership; participation; social interaction; Straussiangrounded theory; symbolic interactionism

On 15 March 2019, an extremist white supremacist killed 51 innocent Muslim people at Al Noor Mosque and the Linwood Islamic Centre in Christchurch, a tragedy which deeply shocked Aotearoa New Zealand society. This horrific incident, described as "New Zealand's Darkest Day," raised important questions of how people with different racial backgrounds live together in society. By revisiting the country's carefully constructed image of racial harmony (Duncan, 2007), the
Christchurch mosque attacks led to more societal efforts towards embracing ethnic diversity in order to build an inclusive society.

In the past, Aotearoa New Zealand society was considered bicultural, being made up of Māori as tangata whenua (the indigenous peoples) and (predominantly) British settlers (Cheyne et al., 2008), until a change in immigration policy occurred in the 1980s. In 1986, for example, $87 \%$ of Aotearoa
AOTEAROA

NEW ZEALAND SOCIAL WORK 33(1), 29-43.

CORRESPONDENCE TO: Hagyun Kim H.kim2@massey.ac.nz 
New Zealand's population was European, followed by Maori (9\%) and Asians (1\%) (Jackson \& McRobie, 2005). Since then, a massive inflow of Asian immigrants has contributed to increased ethnic diversity. According to the 2018 Census, $70.2 \%$ of Aotearoa New Zealand's population is of European ethnic origin, 16.5\% Māori, 15.1\% Asian and $8.1 \%$ Pacific, followed by $1.2 \%$ from Middle Eastern, Latin American and African countries (Statistics New Zealand, n.d.). The Asian community is often referred to as a mostly-immigrant community, based on the fact that the majority arrived in Aotearoa New Zealand recently, while acknowledging their presence in this land since the early 1800s (King, 2003).

Given the increase of Asian immigrants, achieving social cohesion-which is vital in the functioning of a stable society (Kate et al., 2018)—requires the promotion of Asian participation in society. In response, the New Zealand Settlement Strategy was launched in 2004 with a belief that "New Zealand's prosperity is underpinned by an inclusive society, in which the local and national integration of newcomers is supported by responsive services, a welcoming environment and a shared respect for diversity" (Department of Labour, 2004, p. 9). Nevertheless, there are replicated reports that Asian immigrants find participation in society to be challenging due to the complexity of the acculturation process (Ho, 2015), coupled with a prejudiced social reception towards them (Kim \& Hocking, 2016), while Aotearoa New Zealand's sociopolitical systems are ill-prepared to serve their needs for participation (Wright-St Clair et al., 2017).

\section{Asian immigrants in the Aotearoa New Zealand context}

Despite the lasting historical controversy surrounding the text of Te Tiriti o Waitangi, with the Māori and English versions containing significantly different meanings (Cheyne et al., 2008), there is no doubt that

"Aotearoa is the tūrangawaewae of Tangata
Whenua" (ANZASW, 2019, p. 6). At the very least, Te Tiriti o Waitangi guarantees Māori rights to a governance relationship with the British Crown (Ruwhiu, 2001). To that end, Te Tiriti o Waitangi requests a reciprocally respectful relationship with Māori. The author firmly insists that Asian immigrants are Tauiwi (non-Māori) in this land and must protect and preserve the indigenous rights of Māori at every level.

The spirit of Te Tiriti has raised an awareness of cultural safety in society and creates a path for the co-existence of different races in Aotearoa New Zealand (Briggs, 2001, cited in Pepworth \& Nash, 2009). Te Tiriti o Waitangi requires all Tauiwi to be aware of and respect Māori traditions and worldviews, while its spirit promises ethnic minority peoples' rights to stay connected with their cultural origins (Nayar, 2013). To this degree, it should be noted that the Asian immigrant community is not homogeneous in the Aotearoa New Zealand context, but is made up of 34 different ethnic groups; each with several sub-ethnic groups (Ho, 2015). Such diversity is an indication that big differences inevitably occur within the Asian community itself, including different demographic characteristics, culture, and languages. Thus, labelling Asians as one group is problematic.

As such, understanding their stories and different cultural backgrounds separately where possible is vital in addressing Asian immigrants' respective needs for participation in society. This paper focuses on Korean immigrants, whose stories are often unheard and overshadowed by the larger and more established Asian groups such as Chinese and Indian communities (Park \& Anglem, 2012).

\section{Korean immigrants in Aotearoa New Zealand}

Despite the more than 70-year relationship between the two countries, the number of Koreans immigrating to Aotearoa New Zealand has grown over a relatively 
short period of time. In 1991, for example, only 930 Koreans resided in the country, compared with 30,792 by 2006 (Statistics New Zealand, 2006). This figure indicates that the majority of Koreans are the firstgeneration immigrants, having lived less than two decades in Aotearoa New Zealand. According to the Ministry of Foreign Affairs of the Republic of Korea (ROK) (2019), fewer than 38,114 Koreans lived in Aotearoa New Zealand in 2019, comprising the fourth-largest Asian ethnic group in New Zealand after Chinese $(231,387)$, Indian $(221,916)$ and Filipino $(72,612)$ (Statistics New Zealand, n.d.).

The majority of Aotearoa New Zealand's Korean immigrants live in the greater Auckland region. Many are monolingual and rely heavily on ethnic resources to continue their lives in the host society (Kim \& Hocking, 2016) with a hybrid KoreanNew Zealand identity (Epstein, 2006). These demographic characteristics result in their encountering a range of constraints in transition, including language barriers, disruption of support networks, and difficulty in employment, leading to Korean immigrants' social isolation and economic marginalisation (Chang et al., 2006; Kim \& Hocking, 2018). This may explain the 2\% decline in their numbers between 2006 and 2013 (Statistics New Zealand, 2013), as Korean immigrants returned to their home country or on-emigrated to countries such as Australia or Canada.

Korean immigrants have their own cultural and linguistic backgrounds distinct from those of other Asian groups. It is therefore necessary to understand their unique challenges and needs in relation to facilitating their participation in society. Despite the availability of a small number of studies relating to the degree of acculturation, identity, cultural beliefs, and employment (Chang et al., 2006; Epstein, 2006; Kim \& Hocking, 2016; Park \& Anglem, 2012), the issues related to Korean immigrants' settlement have been sparsely heard or addressed. Questions concerning the meaning Korean immigrants attach to their life in their new country still remain unanswered. The purpose of this study is to recognise issues Korean immigrants encounter in Aotearoa New Zealand and to explore how they reconstruct life-meaning in response to these issues.

\section{Social work with Asian immigrants}

Despite Aotearoa New Zealand's ethnic diversity, racial inequality still exists (Cheyne et al., 2008), limiting Asian immigrants' options for making healthy lifestyle choices. Scholars also report that discrimination, racism and even hostility prevail towards Asian immigrants, and this prejudiced social reception closely relates to their socio-political marginalisation, creating formidable barriers to equal citizenship (Ho, 2015; Kim \& Hocking, 2016). In the light of this, the social work profession can offer itself as a strong ally to this population, reducing the inequalities faced by this group through its strong advocacy for social justice and human rights (Palattiyil et., 2019; Viola et al., 2018).

Aotearoa New Zealand's immigration policy no longer focuses solely on importing immigrants into the country, but also on guaranteeing their integration into society. Integration entails a process of new immigrants adapting to new social norms while their traditions are valued (Berry, 2008). Social workers can assist with this process when they empower Asian immigrants with limited ability to engage in the host society. By restoring the adaptive balance between people and their environment (Payne, 2014), social workers can help create conditions where Asian immigrants experiencing "lack of resources, social barriers, intolerance, and negative prejudices of the host population" (Fazzi, 2012, cited in Viola et al., 2018, p. 484) are able to reach their full potential. Indeed, in their practice, many social workers are already at the forefront of the effort to address Asian immigrants' life challenges, as they work to increase immigrants' social 
skills and social opportunities, alongside strengthening the community's capacities to solve immigrants' transitional life challenges.

Working with ethnic minority groups requires cultural competence, including social workers' tolerance of difference, understanding of various cultural norms, and an ability to communicate crossculturally (ANZASW, 2019). Some have critiqued, however, that despite the complexity of immigrants' settlement processes, social workers' knowledge remains "naïve, voluntary and experiencebased" (Barberis \& Boccagni, 2014 cited in Viola et al., 2018, p. 484). In particular, due to insufficient resources reflecting ethnic diversity in society (Wright-St Clair et al., 2017), little training is available for social workers to acquire knowledge and skills relevant to Asian immigrants' life challenges, sometimes contributing to an avoidance of working with them (Palattiyil et al., 2019). The outcomes of this research have the potential to contribute towards acquisition of knowledge and skills with which social workers can more competently work with Asian immigrants and promote their integration into society.

\section{Theoretical stance}

Symbolic interactionism theoretically underpins this study, with its belief that meaning is constructed through the process of self and social interaction (Blumer, 1969); that meanings emerge only when a person's consciousness engages with objects in the world they interpret (Charon, 2010). Epistemologically, symbolic interactionism is located within a constructionist paradigm that attests "meaning and experience are socially produced and reproduced, rather than inheriting within individuals" (Burr, 1955 cited in Braun \& Clarke, 2006, p. 85).

In symbolic interactionism, the self refers to a process through which a person interprets others' actions by putting oneself in the place of the other (Charon, 2010), which is only possible through significant shared symbols (Blumer, 1969). The central notion of symbolic interactionism is, therefore, a process of interpretation through which a person constructs oneself and creates the world of experience in which they live. This notion helps us appreciate that objects are not inherently meaningful; rather, people assign meaning through interaction.

In addition, the author aligns with structurally oriented symbolic interactionism from Stryker (1980) and Shibutani (1955) who attested that the self is constructed through interaction at the crossroads of social institutions. From their points of view, the self and the environment are inseparable, as the environment potentially offers opportunities as well as constraints; that is to say, "both society and person are abstractions from on-going social interaction" (Stryker, 1980, p. 2). Their ideas help the author to appreciate "who I am depends on the ' $\mathrm{Me}^{\prime}$ that is called forth by the social context" (Bowers, 1988, p. 37). In this context, it is equally important to examine societal contexts as much as the process of self/social interaction.

\section{Methods}

Grounded theory guided the study design, a methodology designed to study a person as an active actor who takes a role in responding to situations on the basis of the meanings they construct through social interaction (Glaser \& Strauss, 1967). For grounded theorists, "knowledge arises through the acting and interacting of self-reflective beings, and those activities are typically precipitated by a problematic situation, where one cannot automatically or habitually respond" (Corbin \& Strauss, 2008, p. 2). Admittedly, the analytic focus of this study was participants' actions in problematic situations and the meanings they attach to those actions in the host society.

Furthermore, grounded theory is relevant to a relatively unknown population by producing an explanation grounded in the data. Just as human beings interact with each 
other through the process of taking the role of the other, grounded theorists attempt to take the role of the research subject (Corbin \& Strauss, 2015). Through this process, grounded theorists immerse themselves in the world of the research subjects and as a result, remain close to the experiences of the people they study (Glaser \& Strauss, 1967). In this sense, grounded theory is a particularly useful method when investigating Korean immigrants whose settlement issues are under-researched or not known.

In particular, the author followed the guidelines of Straussian-grounded theory, which holds that the meanings of social action rest on the context in which they appear (Corbin, 2009). That is to say, the process of actors' meaning-making must be explored within social and political contexts. From their point of view, a range of contextual conditions determine people's actions / interactions; thus, relating a person's inter/actions to structure is an essential step in analysing what is happening in the real world (Strauss, 1987). Bringing the societal structure into the participants' actions when analysing their stories is relevant to this study, as immigrating to a new country inevitably involves interaction at both the individual and societal levels (Nayar, 2013).

\section{Recruitment}

To be eligible, participants were required to satisfy the following criteria: (i) aged 20 years and over; (ii) had immigrated from South Korea after 2000; (iii) had lived in New Zealand for more than three years; and (iv) held New Zealand residency or citizenship. To recruit participants, advertisements were placed in several ethnic newspapers.

Initially, one man and two women contacted the author to express their interest in the study. During the first contact, the author outlined the ethical issues regarding the study as well as informing them of their right to withdraw at any point. A further six participants were recruited through snowball sampling and theoretical sampling whereby the author sought future participants among the existing study subjects' acquaintances (Naderifar et al., 2017), in particular those who could elaborate on concepts derived from previous data analysis (Glaser \& Strauss, 1967).

The interviews occurred between October 2018 and July 2019. The participants selected the date and venue convenient to them for the interview. Nine Korean immigrants aged between 28 and 55 years participated in this study. Six were female. At the time of the interview they had resided in New Zealand between 4 and 19 years (with a mean of 13 years). All the participants resided in the greater Auckland region. Their demographic characteristics are detailed in Table 1.

\section{Data collection}

All interviews were conducted in Korean and lasted approximately 60 minutes. The interviews were semi-structured with openended questions, to allow participants to talk freely about any issues relevant to research questions. Apart from indicative questions, participants were given considerable control over what topics to include and the level of detail they wished to share, with the purpose of listening to their narratives in their voice and from their point of view.

Alongside interviews, a range of alternative sources were collected for the analysis. This included memos for participant observations and articles from ethnic newspapers. A combination of different sources of data helps researchers to have insight into, and be able to give meaning to, the events and happenings in the studied world (Glaser \& Strauss, 1967).

\section{Data analysis}

The author transcribed the interviews verbatim, listening and re-listening to the interviews thus enhancing researcherdriven thinking in grounded theory (Strauss, 1987). Then, three stages of coding were used progressively: open, axial, 


\section{QUALITATIVE RESEARCH}

Table 1. Participants' Demographic Characteristics

\begin{tabular}{|l|c|c|c|c|c|c|c|}
\hline Name & Gender & Age & Marital status & Children & Arrival in New Zealand & Employment status & $\begin{array}{c}\text { City of residence in } \\
\text { New Zealand }\end{array}$ \\
\hline Sook & F & 53 & Married & 2 & 2010 & Employed & Auckland \\
\hline Moon & F & 47 & Married & 2 & 2010 & Employed (Part time) & Auckland \\
\hline Hong & F & 46 & Married & 1 & 2001 & Employed & Auckland \\
\hline Miho & F & 52 & Married & 2 & 2007 & Student & Employed \\
\hline Gahee & F & 55 & Married & 1 & 2003 & Auckland \\
\hline Yong & M & 47 & Married & 2 & 2000 & Auckland \\
\hline Sol & M & 38 & Married & 0 & 2008 & Self-employed & Auckland \\
\hline Jung & F & 28 & Married & 0 & 2001 & Self-employed & Auckland \\
\hline Gong & M & 46 & Married & 3 & 2015 & & Auckland \\
\hline
\end{tabular}

Note. (All names are pseudonyms).

and selective coding, through which the conceptual abstraction of data emerges and its reintegration as theory occurs (Corbin \& Strauss, 2015).

Open coding refers to the initial interpretive stage where the analyst fractures data by words, phrases, and events, and begins to look for patterns of participants' actions and meanings related to those actions. During this process, the author gained lists of open codes strongly linked to participants' narratives and located those codes under categories such as, dreaming of overseas life; struggles in transition; traversing two cultural spaces; and finding a place in communities. At this stage, memo writing was an integral part of the analysis, with the author constantly jotting down ideas and potential coding schemes.

Axial coding refers to re-assembling data in a way that draws attention to the relationships between and within categories (Wicks, 2010). Through constant comparison, categories are related to one another, with some subsumed under more abstract categories, to develop more precise explanatory concepts. The conditional/ consequential matrix is also employed to obtain understanding of a phenomenon's complexity (Corbin, 2009). At this stage, several significant categories emerged such as having language difficulty; seeking ethnic resources; experiencing isolation; approaching neighbours; and volunteering. The author constantly compared those categories and later developed a more abstract category, namely knocking on the door to integration. Upon arrival, most participants initially sought ethnic resources to continue their lives due to language barriers and cultural differences. While mastering new surroundings with the aid of ethnic resources, participants gradually approached neighbours or volunteered to integrate into communities. This category encapsulates a pattern of participants' engagement in communities while positioning other categories as its subcategories, to answer questions such as when, why, how and with what consequences (Corbin \& Strauss, 2015).

Selective coding is the final stage. During this stage, categories are further developed and refined and then brought together to tell a larger story through a heuristic process of reconstruction (Braun \& Clarke, 2006). In other words, the analyst integrates the significant categories to yield a central concept that captures the essence of what is going on in the research field (Corbin, 2009). At this stage, the author hypothesised the central concept of the study as seeking membership in society and continuously checked this proposition against incoming data, to verify this central concept that pulls all other major categories together. In this sense, selective 
coding is "a deductive process" (Price, 2010, p. 2) through which the author concludes that the concept of seeking membership in society is abstract enough to encapsulate the meaning participants pursued in the host society and still be applicable to all cases in the study.

\section{Ethical consideration}

The two main areas for ethical consideration were confidentiality and accuracy. Pseudonyms were employed to protect participants' identities. To enhance accuracy, participants had an opportunity to read the transcription of their interview. The accuracy of the excerpts translated into English was verified by a translator who signed a confidentiality agreement. Ethical approval was granted by the Massey University Ethics Committee in 2018 (ref. 4000019476).

\section{Findings}

For the participants of this study, immigrating demanded a major reconfiguration of their daily routines in communities. The story participants commonly shared related to acculturative stresses, coupled with language barriers, financial hardship and un/ underemployment, with the resultant anxiety, depression and low self-esteem. In response, participants traversed two cultural spaces, entitled "knocking on the door to integration" a strategy by which participants gradually arrive at the point where they accept Aotearoa New Zealand as home. Through this process, participants constantly sought an opportunity to make their existence visible in society; that is to say, they were seeking membership in society. This is a concept which encapsulates the meaning they pursue in communities, in the hope that one day they will be recognised as members of Aotearoa New Zealand society.

\section{Dreams and struggles in transition}

South Korea has achieved rapid economic growth since the 1970s. Paradoxically, this economic success has created a high level of competition in society where excessive working hours, "I had worked hard over the last 10 years and I was so exhausted" (Gong) and academic success is a part of its citizens' lives, "Everything changes so fast in Korea. If you want to survive, you can't be behind" (Hong). For the participants of this study, immigration seemed to be a way of escaping their stressful lifestyle: "I decided to leave the country to refresh my life for myself and my children" (Moon), and seeking a place to restart their life, particularly in Aotearoa New Zealand, a country attractive to them because of its mythology of being clean and green, "I envied New Zealand's green natural environment and people's relaxed lifestyle" (Sol).

In coming to a new country, however, participants encountered unforeseen difficulties. Language barriers and a lack of networks, accompanied by unfamiliarity with new surroundings, impeded their ability to continue with their daily routines. Communication skills in English were essential to rebuilding their place in communities, "If you speak English, everything gonna be ok. But we can't speak English well" (Gahee). Of particular note, many participants struggled to gain employment in their area of expertise due to language barriers, "I was a teacher in Korea but here I worked as a cashier at the ethnic health shop" (Miho). Many participants relinquished many things that were taken for granted at home because of language barriers, in particular in the area of employment. Sook voiced how difficulty in employment resulted in a dizzying effect on her life:

My husband worked at the Korean butchery. He was a successful salesman in Korea. I didn't worry about income at that time ... [here] Our income was minimal, and it made our spending simple. We cut our spending for dining, travel and even donation to church. We had to forget the glory in [the] past and start from scratch here. 
The process of creating a place in communities began regardless of their readiness. It was a highly stress-inducing process in which participants had to learn about their new surroundings with insufficient local knowledge and limited language skills, influenced by several factors at both the social and individual levels. From this perspective, their experience of settlement inevitably resulted in numerous health problems ranging from mental to physical, "it was stressful to look after my family without enough English skills ... My wife recalled, when she asked me to call somewhere in English, she could see how anxious I was on my face" (Gong) and "my father worked hard at the lunch bar. One day he collapsed and is now physically disabled" (Jung), while participants dealt with loneliness and isolation, "I was lonely because I had no one around" (Sol), and encountered a new social status in communities:

I was a person expecting people would normally serve me as they had in Korea ... [Here] I became a kitchen hand. I washed someone's dishes and cleaned their tables. I became a person who serves for other people. It hurts my pride. (Sook)

\section{Knocking on the door to integration}

Participants' actions are always situated in a context of invisible personal and societal determinants. As described earlier, a number of salient conditions adversely impacted on participants' adjustments to a new cultural milieu. In response, participants in this study used a strategy of "knocking on the door to integration." This strategy refers to on-going actions undertaken by participants in response to the situations in which they find themselves. This strategy contains two sets of sub-processes; utilising past knowledge and extending the safe zone to local communities. Given limited resources and support networks, these two sub-processes are commonly employed wherein participants initially seek local ethnic resources to retain a sense of safety, while preparing themselves for the host society.

\section{Utilising past knowledge}

For the participants, re-establishing a home in a foreign country required them to find continuity in life. For participants who had language barriers, utilising past knowledge might possibly be the only way to function autonomously in the host society. They consciously sought a place where they could use their native language and previous knowledge. Through this strategy, participants retained a sense of safety in the host society, and this may explain Korean immigrants' heavier concentration in the Auckland region where they can continue a life in Korean. Miho explained how Korean immigrants easily continue a life in Korean in this city:
Almost everything is available in Korean here. We can find a job or easily start a business ... To go through my day, I don't need to speak English or meet local people if I wish. I can find Korean staff or 1.5 generation Koreans at shops, bank and hospital.

As Miho disclosed, utilising past knowledge refers to participants' behavioural pattern of sticking to ethnic resources and traditions in a foreign country. In this context, participants mostly interacted with their own ethnic groups, "I normally hung out with other Koreans" (Yong). Through this network, participants built a sense of affiliation and friendship as well as eased their loneliness in an unfamiliar environment, "I met my wife when I was a member of the Korean [art] group" (Sol). For Korean immigrants who urgently needed a job for their visa application, utilising past knowledge was not optional but was necessary to continue a life in communities, "I worked at the Korean [...] because the owner promised to support my residency application" (Sook). 
Undoubtedly, a strategy of utilising past knowledge greatly helped participants ease the pressure of settlement in communities. The greatest advantage of this strategy participants commonly reported was that they could learn about their new surroundings with a sense of safety, "at my workplace, we speak in Korean. We don't need to worry about misunderstanding" (Gong). However, while sticking to ethnic resources and traditions, participants also experienced a range of disadvantages, notably social isolation in the host society. Since they mostly engaged in the Korean community where "everyone virtually knows each other" (Miho), they likely preserved the old lifestyle in Aotearoa New Zealand, "although my business is hardly profitable, I couldn't charge some of my friends. It is our culture, how could I?" (Sook), and experienced social isolation, " at school, my children always hung out with other Koreans. They hardly made local friends ... It wasn't what I expected here. I felt we lived in Korea" (Moon).

Of particular note, exploitation in the labour market was concerning in the Korean community, "I had to do extra jobs outside my job description. It was common because of the small size of Korean businesses" (Sol). The degree of exploitation seemed to increase when a job was necessary for participants' visa status. This included unpaid overtime work, "I haven't asked overtime pay because they didn't like it" (Gahee), unfair treatment, "the boss knew I needed this job for my visa ... I wasn't in a position to negotiate my pay or working conditions" (Gong), and emotional abuse, "yelling is normal for small mistakes" (Sook). Sook was in tears when she recalled her experience of working at the Korean business:

The boss knew I needed this job for my visa, so he could demand everything he wanted but paid me less. If he was unhappy with my performance, he was easily upset. Every day after work, I didn't go home right away. I calmed down myself or sometimes cried for a while at the local park, so my family didn't worry about me.

\section{Extending the safe zone into local communities}

This strategy refers to participants' efforts to approach the host society. While utilising past knowledge, participants gradually mastered their new surroundings leading to their increased readiness to approach the host society. In this sense, the Korean community can be "a steppingstone for integration" (Gong). For participants with insufficient English skills, perhaps the first place they sought outside their safe zone was a place where they hoped to improve their language skills. For many participants, speaking a local language crucially determined their involvement in many areas of social settings, "My application wasn't successful because of my English" (Sol), with a result that participants regarded language skills as a panacea for their participation in society, "if you speak English, you won't have any problem here" (Sook). Thus, participants made constant efforts to improve their English skills, "my wife now learns English at the community centre" (Gong), in particular by interacting with local people, "I joined a local Toastmaster club to learn English as well as meet local people" (Gahee).

Despite a number of participants retaining a job or running small businesses in the Korean enclave that required little or no communication skills in English, some participants began to set up businesses which served local people, "we bought a sushi shop from a Korean agent and most of our customers were locals" (Sook). Some participants worked at Korean businesses whose customers were mostly local people, "I worked at the [...] shop. I had lots of opportunity to practice my English with locals. It was so helpful" (Gong). This experience played a role in increasing participants' local knowledge and helped them extend their safe zone outside the 
Korean enclave, "my work experience at the Korean [...] was helpful when I got this job at a local business" (Sol).

Some participants sought a place in communities where they used their transnational knowledge. For example, Miho secured a job in which she could utilise her native language, "I teach Korean at the local primary schools". Gahee also worked at the local agency with her transnational knowledge, "When I looked for a job, my agency also needed someone to support Korean immigrants". Other participants used a local recruitment agency to find a job in their community, "I had a job offer through a recruitment agency. They helped me to get a job matching my profile" (Sol).

For the participants, having a job played a significant role in supporting themselves and their families as well as connecting them with the host society. Participants in this study showed that they continued to seek jobs in which they interact with the host society. Gong was determined to find a job in the host society:

Over the last few years, I kept applying for the same job. It is my dream job here. Every time when my application was declined, I checked what I missed ... I will improve relevant skills to that job and keep applying for it until I get it.

Apart from areas in employment, there was a range of opportunities that helped to extend the safe zone into their local communities. Some participants joined in volunteer work with the hope of improving their English skills as well as building networks with local people: "Many Koreans want to be a volunteer because they believe it helps to learn English and meet locals" (Hong). For participants with school-aged children, schools seemed to be a place where they could extend the safe zone into their communities, "I did volunteer at several events at my daughter's school ... Through those events, I met many local parents"
(Yong). To extend the safe zone into their local communities, some participants were courageous enough to knock on the door of a local club where they did not have any previous connection, "I just visited the local Lions club and asked them how I join. I joined the club because I wanted to know the community where I lived" (Gahee).

While extending the safe zone into their local communities, the degree of their participation was inseparable from the reception they encountered, "When my son started school, my wife was hesitant to go to classroom because of her English ... Some kiwi parents always hugged her and welcomed her at school" (Gong). Participants greatly appreciated the support they received when approaching the host society, "I have received lots of support from local people" (Moon). Gahee described the welcoming reception she received at her club and explained how it contributed to her long-term engagement in the club:

Why have I been a member for 10 years? Umm, maybe kind people. They don't treat me differently nor discriminate my differences. People accept and respect my differences. They even appreciate my presence at the club saying my differences will flourish the club culturally.

Upon arrival, participants initially utilised past knowledge, seeking ethnic resources which helped them to learn about their new surroundings with a sense of safety. With this confidence, participants gradually extended the safe zone into their local communities, particularly to places where they received welcoming and supportive receptions. This is a strategy commonly employed by participants through which they eventually arrived at the point of mastery in their communities: "I feel settled now. I know people around me and what happens in the community. I can speak English a little, not fluently but enough to express myself" (Hong). 


\section{Seeking membership in society}

The concept of seeking membership in society is the meaning which participants aspire towards when they settle in Aotearoa New Zealand. Participants continually seek opportunities through which they can be recognised as members of Aotearoa New Zealand society. By utilising ethnic resources and extending their engagement into local communities, the participants reported that they became to acknowledge new lifestyles while accepting Aotearoa New Zealand as a home, "Yes, we are still financially tight. But I don't care too much about it now. I love to live with clean air and beautiful nature here. This is my home now" (Moon). At this stage, the main point participants wished to make was that they did not hope for assimilation, "no matter how long I live and I like [it] here, I think I am Korean" (Moon). Nonetheless, they appreciated the opportunities that their new home country offered to them, "I prefer relaxed lifestyle here" (Gong) and "we have more opportunities here. We can start a new thing anytime regardless of our age" (Gahee).

In the meantime, participants reported that their membership in society was not automatically granted, "to be honest, we are not equal. You can hear lots of those stories from media" (Moon), despite the perception of New Zealand's racial harmony, "I chose New Zealand because I heard it has a low level of racism and crime" (Gong). In addition, the small size of the Korean population contributed to their invisibility in society, which impacted on their sense of belonging in society as Hong described:

Maybe a Kiwi is European? Media also often depicts them as a kiwi. I love to call myself a kiwi, but people don't think we are. What's the point ... unless society believes we are.

Participants constantly pursued membership of the society while accepting
Aotearoa New Zealand as a home. They sought and engaged in activities with which they made their presence visible in communities, with the hope that they would obtain a sense of fitting in as well as being included within communities, "at my workplace, I always shared my Korean style lunch. Later people loved it and often asked me how and where to buy it" (Gahee). It was through making their presence visible, "I want to do something for this country" (Yong), that participants sought recognition in relation to gaining membership and making a contribution to their new home country, "I want to organise something in a name of Korean people so people know we are here and doing something for the country" (Gong).

Participants engaged in a range of activities with which they made their presence visible, with the purpose of seeking recognition as members of society. Noticeably, many participants began to make their presence visible at workplaces, "I do my best for my job. They gave me a chance to work and in return, I want to do something for them" (Sook) and "my manager told me she was impressed by my work ethic" (Hong). Some participants made an effort to enrich cultural diversity in communities, "I organised a Korean night event at my club" (Gahee), while others enhanced their ethnic community's success in society, "I taught at the Korean school. I helped Korean children learn Korean and develop Korean identity" (Miho), in particular, connecting ethnic people with the host society: “Many people don't know about local services available to them. I do lots of presentations regarding what kind of services are available to Korean seniors" (Yong).

For participants, the point at which they feel they have obtained membership closely relates to the extent to which their presence is visible and valued in the community, with a hope of contributing to their own ethnic community as well as the host community. According to Gong, making himself visible 
refers to being recognised as a member of society:

We are invisible here, you know, in election or national event? We don't make our voice ... I want to do something the society recognise us. Maybe express our opinions or participating in events in a name of Korean people.

In summary, participants disclosed that they rebuilt their lives in the host society through a strategy of "knocking on the door to integration." This strategy helped them gradually master their new surroundings and accept New Zealand as their home. In the meantime, participants constantly sought and engaged in activities, with the hope of obtaining membership in society. Seeking membership in society has the greatest explanatory relevance to encapsulate the life meaning that Korean immigrants pursued in New Zealand.

\section{Discussion}

Despite immigration being a global phenomenon in the 21st century, there are replicated findings that the age of immigration (Castles \& Miller, 2009) arrived without society's readiness to live together (Wright-St Clair et al., 2017), with the resultant socio-economic marginalisation of immigrants and ethnic divisions in society (Ho, 2015; Kim \& Hocking, 2016).

The majority of studies about immigrants in the Aotearoa New Zealand context have been framed as an acculturative process (Berry, 2008), employing the concepts of assimilation, separation, marginalisation and integration, based on their strategy of adapting to life changes in a new country (Chang et al., 2006; Epstein, 2006; Ho, 2015; Park \& Anglem, 2012). More recent studies, however, suggest that settling involves a process of negotiating control over their lives (Kim \& Hocking, 2016; Nayar, 2013) falling into six major clusters: "family; social dislocation and alienation; cross-cultural concerns; support and services; employment, education, and language; and community" (Kate et al., 2018, p. 463). It is crucial to note that immigrants' experiences within these main areas differ due to their different status of entry, skills and life situations, and this heterogeneity contributes to society's incapacity in generalising and meeting their needs as a whole.

To ensure immigrants' success in Aotearoa New Zealand, the government launched the settlement strategy in 2004. This strategy aims to ensure immigrants' participation in society by: (i) feeling welcome and accepted; (ii) being in the right job; (iii) being housed well; (iv) speaking and understanding New Zealand English; (v) knowing how to access information and services; and (vi) understanding New Zealand's way of life (Department of Labour, 2007). This strategy is an integrated framework in which the local and national integration of immigrants is supported by responsive services, a welcoming environment and a shared respect for diversity (Department of Labour, 2004). It has been almost two decades since the government began to consider the everyday needs of immigrants. The focus is clearly on assisting newly arrived immigrants to master things reflective of Aotearoa New Zealand society. This societal effort was somewhat fruitful, in that many immigrants gradually accepted Aotearoa New Zealand as home while obtaining a sense of mastery in communities, "I feel settled now" (Hong). This would be a starting point in relation to building an inclusive society where all people can participate in their communities.

Participants, however, reported that the mastery of new surroundings through different stages of the acculturative process is not the end of their settlement journey, since having a sense of mastery does not necessarily determine their membership in society. Despite a relatively long period of residence and knowing their new surroundings, participants' ethnic minority status is often associated with their lack of belonging in society, "no matter how long 
I live here, I think I am Korean" (Moon). In this sense, the author suggests that immigrants' settlement journeys do not stop at the point of mastery of new surroundings, but continue until they have true membership in society. Thus, the emphasis of the government's support should be promising immigrants' membership in society while guaranteeing their equal participation in communities.

Admittedly, the author argues that a sense of mastery in new surroundings should not be the final outcome in determining immigrants' success in the host society, as long as they experience a situation in which the statement, "I don't think we belong here" (Moon) still holds true. This finding is congruent with previous research findings that immigrants constantly seek a place in society where their presence is recognised and valued (Kim \& Hocking, 2016, 2018). Participants disclosed that membership in society contributes to an increasing sense of belonging and subsequently enhancing their quality of life, "I am grateful to live here and appreciate the support I have received from society. Now it is time for me to return something to society" (Yong). It is a necessity that the Aotearoa New Zealand government further commits to developing an atmosphere in which immigrants' membership can be promoted as integral to becoming a flourishing society.

\section{Implications for social work in Aotearoa New Zealand}

In principle, social work is a profession promoting social cohesion and collective responsibility (IFSW, 2014). In line with this principle, social work in Aotearoa New Zealand has two central focuses: i) to empower people and communities; and ii) to engage in action to change the structures of society that perpetuate injustice (ANZASW, 2019). This perspective provides a useful framework in which social workers consider the interplays of context between the numerous actors involved in the settlement process to address Asian immigrants' transitional life challenges in communities.

For many Asian immigrants, social workers might be the first people they engage with in seeking support. With an emphasis on a systematic approach in the profession (Payne, 2014), social workers have the strengths to alleviate social suffering and improve the quality of Asian immigrants' lives through interventions at the micro, meso, and macro levels; for example, increasing individuals' problem-solving skills while mobilising the community's resources and challenging institutional racism. A systematic approach is necessary wherein social workers empower Asian immigrants to make the host society their home, as well as linking support from government agencies, local communities, civil partners, volunteers, and ethnic selfhelp groups.

In particular, the findings of this study suggest that Asian immigrants make a continual effort to obtain membership in society. This effort possibly led them to having an opportunity to represent their home country, "whenever I met local people, I consider my behaviours may represent my community" (Yong), as well as flourishing in their new country, "At my Uni course, my lecturer and students liked my presentations. They said because of my presence in class, they could better understand Asians and their culture" (Gahee). In this sense, the author recommends that social workers' abilities in this field can be enhanced if they support Asian immigrants to secure "a valid role to play in contributing to, and helping construct, local community and society at large" (Nayar, 2013, p. 385).

Social work in the Aotearoa New Zealand context cannot be separated from the diverse cultural groups that exist here and this environment requires social workers to have sufficient knowledge and skills to work with ethnic minority groups (ANZASW, 2019). It is crucial for social workers to have adequate knowledge of Asian immigrants' 
resettlement processes. Specifically, this includes understanding the life meaning that Asian immigrants pursue in a new country while dealing with acculturative stresses and social inequalities prompted by their ethnic minority status in society.

\section{Limitations}

Within the paradigm of constructionism, "data are not in an epistemological vacuum" (Braun \& Clark, 2006, p. 84). This leads to the findings being co-constructed by the analyst and participants (Corbin \& Strauss, 2015). The trustworthiness criteria suggested by Lincoln and Guba (1985) (credibility, transferability, dependability and confirmability), were carefully used to ensure the findings accurately captured the participants' experiences. The strategy of member checking was adopted to gain credibility and having multiple sources of data increased transferability. To enhance dependability and confirmability, the findings were validated by peers, alongside the self-reflexive stance.

All participants were aged between 28 to 55 years and resided within the greater Auckland region since 2000. This demographic character led to the fact that the findings may not fully embody stories of Korean immigrants, in particular those who settled outside of this city and the 1.5 Korean immigrant generation. Verifying the concept of "seeking membership in society" across a range of ages, arrivals and locations is a research avenue to be pursued.

\section{Conclusion}

The participants' stories revealed severe disruption in many areas of their social settings, coupled with their ethnic minority status. In response, participants employed a strategy of "knocking on the door to integration." This is a process in which participants gradually extend their safe zone to local communities while maintaining a sense of safety by seeking ethnic resources. The concept of seeking membership in society encapsulates the participants' pursuit of their settlement journey, until they feel they are recognised as members of the society.

Ethnic diversity is a reality that social workers encounter in Aotearoa New Zealand, and this requires them to have sufficient knowledge and skills in relation to work with ethnic minority groups. The findings of this study suggest that social workers should not only assist Asian immigrants in mastering their new surroundings, but also endorse the meaning they pursue in a new country. This would allow social workers to enhance Asian immigrants' participation in the host society.

Accepted 20 January 2021

Published 23 April 2021

\section{References}

ANZASW. (2019). Code of ethics. https://anzasw.nz/ wp-content/uploads/Code-of-Ethics-Adopted-30Aug-2019.pdf

Berry, J. W. (2008). Globalisation and acculturation. International Journal of Intercultural Relations, 32(4), 328-336. doi:10.1016/j.ijintrel.2008.04.001

Blumer, H. (1969). Symbolic interactionism: Perspective and method. Prentice-Hall.

Braun, V., \& Clarke, V. (2006). Using thematic analysis in psychology. Qualitative Research in Psychology, 3(2), 77-101. doi:10.1191/1478088706qp063oa

Bowers, B. J. (1988). Grounded theory. In B. Sarter (Ed.), Paths to knowledge: Innovative research methods for nursing (pp. 33-59). National League for Nursing.

Castles, S., \& Miller, M. (2009). The age of migration (4th ed.). Palgrave Macmillan.

Chang, S., Morris, C., \& Vokes, R. (2006). Korean migrant families in Christchurch: Expectations and experiences. The Families Commission.

Charon, J. M. (2010). Symbolic interactionism (10th ed.). Pearson.

Cheyne, C., O’Brien, M., \& Belgrave, M. (2008). Social policy in Aotearoa New Zealand (4th ed.). Oxford University Press.

Corbin, J. (2009). Taking an analytic journey. In J. M. Morse, P. N. Stern, J. Corbin, B. Bowers, K. Charmaz, \& A. E. Clarke (Eds.), Developing grounded theory: The second generation (pp. 35-54). Left Coast Press.

Corbin, J., \& Strauss, A. (2008). Basics of qualitative research: Techniques and procedures for developing grounded theory (3rd ed.). Sage Publications.

Corbin, J., \& Strauss, A. (2015). Basics of qualitative research (4th ed.). Sage Publications. 
Department of Labour. (2004). Our future to together: New Zealand settlement strategy. Author. http://www.ssnz. govt.nz/publications/NZSettlementStrategy.pdf

Department of Labour. (2007). Settlement national action plan: New Zealand settlement strategy. Author. http://www.ssnz.govt.nz/publications/ NZSettlementActionPlan.pdf

Duncan, G. (2007). Society and politics: New Zealand social policy (2nd ed.). Pearson.

Epstein, S. (2006). Imagining the community: Newspapers, cyberspace and the (non-) construction of Korean-New Zealand identity. In H. Johnson \& B. Moloughney (Eds.) Asia in the making of New Zealand (pp. 147-162). Auckland University Press.

Glaser, B. G., \& Strauss, A. (1967). The discovery of grounded theory. Aldine de Gruyter.

Ho, E. (2015). The changing face of Asian people in New Zealand. New Zealand Population Review, 41 95-118.

IFSW. (2014). Global definition of social work. https://www. ifsw.org/global-definition-of-social-work/

Jackson, K., \& McRobie, A. (2005). Historical dictionary of New Zealand (2nd ed.). Scarecrow Press.

Kate, A., Verbitshy, J., \& Wilson, K. (2018). In different voices: Auckland refugee communities' engagement with conflict resolution in New Zealand. Journal of International migration and Integration, 20(2), 459-477. doi:10.1007/s12134-018-0619-4

Kim, H., \& Hocking, C. (2016). Attending to immigrants everyday activities: A new perspective on ensuring Asian immigrants' quality of life. Aotearoa New Zealand Social Work, 28(3), 57-66.

Kim, H., \& Hocking, C. (2018). A grounded theory of Korean immigrants' experiences of re-establishing everyday activities in New Zealand. Journal of Immigrant and Refugee Studies 16(3), 255-274. doi:10.1080/15562948. 2016.1272732

King, M. (2003). History of New Zealand. The Penguin Group. Lincoln, Y. S., \& Guba, E. (1985). Naturalistic inquiry. Sage.

Ministry of Foreign Affairs (ROK). (2019). Korean diaspora. http://www.mofa.go.kr/www/wpge/m_21509/contents.do

Naderifar, M., Goli, H., \& Ghaljaie, F. (2017). Snowball sampling: A purposeful method of sampling in qualitative research. Strides in Development of Medical Education, 14(3), 1-4. doi:10.5812/SDME.67670

Nayar, S. (2013). The treaty of Waitangi: Framing immigrants' occupational practices in Aotearoa New Zealand. Journal of Occupational Science, 20(4), 382-395. doi:10.1080/14427591.2013.801102

Palattiyil, G., Sidhva, D., Pawar, M., Shajahan, P., Cox, J., \& Anand, J. (2019). Reclaiming international social work in the context of the global agenda for social work and social development: Some critical reflections. International Social Work, 62(3), 1043-1054. doi:10.1177/0020872818774107

Park, H., \& Anglem, J. (2012). The "trans-nationality" of Koreans, Korean families and Korean communities in Aotearoa New Zealand: Implications for social work practice. Aotearoa New Zealand Social Work, 24(1), $31-40$

Payne, M. (2014). Modern social work theory (4th ed.) Palgrave Macmillan.
Pepworth, J., \& Nash, M. (2009). Finding "a safe place to cry": A review of research and evidence informing social work with refugees and new settlers in Aotearoa New Zealand. Aotearoa New Zealand Social Work, 21(1/2), 48-59.

Price, J. M. C. (2010). Coding: Selective coding. In A. J. Mills, G. Durepos, \& E. Wiebe (Eds.), Encyclopedia of case study research. SAGE. http://dx.doi. org/10.4135/9781412957397.n56

Ruwhiu, L. A. (2001). Bicultural issues in Aotearoa New Zealand social work. In M. Connolly (Ed.), New Zealand social work: Context and practice (pp. 54-71). Oxford University Press.

Shibutani, T. (1955). Reference groups as perspectives. The American Journal of Sociology, 60(6), 562-569.

Statistics New Zealand. (n.d.). New Zealand's population reflects growing diversity. https://www.stats.govt.nz/ news/new-zealands-population-reflects-growing-diversity

Statistics New Zealand. (2006). Quickstats about culture and identity 2006 census.

Statistics New Zealand. (2013). 2013 Census ethnic group profile: Korean. http://www.stats.govt.nz/Census/2013census/profile-and-summary-reports/ethnic-profiles. aspx?request_value $=24754 \&$ tabname $=$ Keyfacts

Strauss, A. L. (1987). Qualitative analysis for social scientists. Cambridge University Press.

Stryker, S. (1980). Symbolic interactionism: A social structural version. The Blackburn Press.

Viola, E., Biondo, E., \& Mosso, C. (2018). The role of social workers in promoting immigrants' integration. Social Work in Public Health, 33(7-8), 483-496. doi:10.1080/19 371918.2018.1546252

Wicks, D. (2010). Coding: Axial coding. In A. J. Mills, G. Durepos \& E. Wiebe (Eds.), Encyclopedia of case study research. SAGE. doi:10.4135/9781412957397.n54

Wright-St Clair, V., Nayar, S., Kim, H., Wang, S., Sodhi, S., Chung, A., \& Hu, C. (2017). Late-life Asian immigrants managing wellness through contributing to socially embedded networks. Journal of Occupational Science, 25(1), 51-64. doi:10.1080/14427591.2017.1370607 